\title{
Endoscopic submucosal dissection for rectal neoplastic lesions: experience from a European center.
}

\section{Type}

Research paper

\section{Keywords}

endoscopic submucosal dissection, rectal tumor, rectal neoplasia

\begin{abstract}
Introduction

Nowadays, various endoscopic resections including polypectomy, endoscopic mucosal resection (EMR), and endoscopic submucosal dissection (ESD) are well known first-line approaches for early neoplastic rectal tumors.
\end{abstract}

Material and methods

In this case series study, we analyzed 320 ESD procedures performed in a high-volume colorectal center in Poland, Europe. The aim of this study was to retrospectively evaluate ESD procedure in cases of rectal carcinoma performed by a single trained operator in a referral center provided with endoscopy.

\section{Results}

Overall, en bloc resection was observed in $92.5 \%$ of patients (296/320). The en bloc resection rate was at a similar level in those lesions with involved anal sphincters versus tumors without involvement $(93.85 \%$ vs. $92.16 \%$; $p=0.644)$. R0 resection was noted in $89.4 \%$ of patients $(286 / 320)$. The overall curative ESD rate was $85.94 \%(n=275)$. The curative ESD rate in the invasive cancer group reached $52.6 \%(n=20)$. We observed ESD-related adverse events, such as bleeding and perforation, in $3.4 \%$ of patients $(n=11)$.

\section{Conclusions}

We have demonstrated that ESD in rectal tumors is an efficient and safe procedure with a high curative rate, even in difficult lesions. Anal sphincter localization and recurrent character of the lesion have no impact on the final outcomes. The ESD approach should have been considered for all rectal tumors, especially those lesions suspected of superficial mucosal invasion, as it can serve as a staging method and may have been curative for adenomas and cancers limited to mucosa. 
1 Title: Endoscopic submucosal dissection for rectal neoplastic lesions: experience from a

2 European center.

3 Short title: The role of ESD in rectal tumors

4 Authors: Spychalski Micha1 ${ }^{1 *}$, Włodarczyk Marcin ${ }^{2}$, Włodarczyk Jakub², Dąbrowski Igor ${ }^{1}$,

5 Bednarski Piotr $^{1}$, Dziki Adam ${ }^{1,2}$

$6 \quad{ }^{1}$ Center of Bowel Treatment, Brzeziny, Poland

$7 \quad{ }^{2}$ Department of General and Colorectal Surgery, Medical University of Lodz, Haller Square 1, 8 90-624 Lodz, Poland

9

Statements:

11 There is no conflict of interest.

12 There is no grant support or financial relationship.

\section{Corresponding author*:}

17 Spychalski Michał MD, PhD

$18{ }^{1}$ Center of Bowel Treatment, Marii Skłodowskiej-Curie Str. 6, 95-060 Brzeziny, Poland 19 mail: mspych80@gmail.com

21 Word count for the text: 3658 words

22 Word count for the abstract: 342 words 


\section{Abstract:}

Introduction:

Nowadays, various endoscopic resections including polypectomy, endoscopic mucosal resection (EMR), and endoscopic submucosal dissection (ESD) are well known first-line approaches for early neoplastic rectal tumors. However, the limited development of colorectal ESD procedures has been observed due to its demanding steep learning curve and higher risk profile in contrast to EMR.

Material and methods:

In this case series study, we analyzed 320 ESD procedures performed by a single operator (MS) after the finishing learning curve in a high-volume endoscopic and colorectal surgery center in Poland, Europe. The aim of this study was to retrospectively evaluate ESD procedure in cases of rectal carcinoma performed by a single trained operator in a tertiary colorectal referral center provided with endoscopy in Poland.

Results:

Overall, en bloc resection was observed in $92.5 \%$ of patients $(296 / 320)$. The en bloc resection rate was at a similar level in those lesions with involved anal sphincters versus tumors without involvement (93.85\% vs. $92.16 \%$; $\mathrm{p}=0.644)$. R0 resection was noted in $89.4 \%$ of patients (286/320). The overall curative ESD rate was $85.94 \%(n=275)$. The curative ESD rate in the invasive cancer group reached 52.6\% $(n=20)$. We observed ESD-related adverse events, such as bleeding and perforation, in $3.4 \%$ of patients $(n=11)$. In multivariate logistic regression, invasive character of lesion and increasing tumor size were associated with a significantly higher odds ratio of the non-curative ESD procedure. Location, recurrence character, and sex had no predictive value.

Conclusions: 
50 We have demonstrated that ESD in rectal tumors is an efficient and safe procedure with a

51 high curative rate, even in difficult lesions. Anal sphincter localization and recurrent character

52 of the lesion have no impact on the final outcomes. The ESD approach should have been

53 considered for all rectal tumors, especially those lesions suspected of superficial mucosal

54 invasion, as it can serve as a staging method and may have been curative for adenomas and

55 cancers limited to mucosa.

56

57

58 Key words:

59 rectal tumor, endoscopic submucosal dissection, rectal neoplasia 60 


\section{Introduction}

Colorectal cancer (CRC) is the third leading cancer in the western world, accounting for approximately 800000 deaths annually worldwide [1]. Rectal cancer (RC) has been considered and treated as an independent disease due to its primarily extraperitoneal location, potential impairment of anorectal continence and differences in metastatic behavior [2]. The prompt identification and removal of early stage rectal lesions and precancerous lesions are crucial to achieve high quality oncological outcomes [3]. Local resection is particularly desirable in RC patients with low stage of disease, because more extensive surgery may be related with permanent colostomy or anorectal dysfunction, which significantly affects patients' quality of life (QoL) [4]. Based on current guidelines presented by the European Society of Gastrointestinal Endoscopy (ESGE), the cut-off point for low-risk patients suitable for local resection is well defined as SM1 deep invasion, no vessel invasion and no budding [5]. The local resection techniques not only have a clear benefit on the QoL, but also, associated with lower mortality, morbidity and total costs, in comparison to elective surgery and that is the way they are getting more popular in clinical practice $[6,7]$.

Nowadays, transanal endoscopic microsurgery (TEM), transanal minimally invasive surgery (TAMIS) and various endoscopic resections, such as polypectomy, endoscopic mucosal resection (EMR), and endoscopic submucosal dissection (ESD) are well known first-line approaches for early neoplastic rectal tumors. All techniques are standard of care, but a direct evidence-based conclusion is lacking. The guidelines by the Japan Gastroenterological Endoscopy Society (JGES) and ESGE suggested to consider the ESD procedure in all rectal lesions suspected for superficial submucosal invasion (SMI) or tumors that cannot be resected en bloc in EMR technique [8]. Moreover, the American Gastroenterological Association (AGA) has also recommended ESD for selected rectal tumors, especially those with suspected SMI [9]. The development of ESD in rectal lesions still has been limited due to a higher risk 
of adverse events, such as bleeding and perforation, demanding steep learning curve, and significant differences in training prospects in comparison to Asian endoscopic centers [1013]. There is still a lack of data from Western countries covering ESD implementation in the rectal tumors. Recent studies have shown that ESD may be a safe and efficient approach for the management of low rectal tumors [14-17]. The aim of the study was to retrospectively evaluate ESD procedure in cases of rectal carcinoma performed by single trained operator (who fulfilled the training according to the ESD curriculum developed by the ESGE) in a tertiary colorectal referral center provided with endoscopy in Poland.

\section{Material and methods}

\section{Study population}

This single-center, retrospective analysis of a prospectively built database was conducted in patients who underwent ESD procedure for rectal tumor from 2016 to 2020 at Center of Bowel Treatment, Brzeziny, Poland by a single operator (MS). Rectal tumors were defined as any lesion, which upper margin was located within $18 \mathrm{~cm}$ length from the anal verge and/or when at least half of the lesion was situated within $15 \mathrm{~cm}$ from the anal verge. Indication for ESD procedure included granular-type laterally spreading tumors (LST-Gs) or mixed LST of $\geq 20 \mathrm{~mm}$, nongranular-type laterally spreading tumors (LST-NGs) of $\geq 20 \mathrm{~mm}$, and tumors difficult to remove completely with EMR (i.e., lesions after failed EMR, those located near or at the dentate line, or those with non-lifting sing). Patients with neuroendocrine tumors, gastrointestinal stromal tumors, and patients with underlying inflammatory bowel disease and familial adenomatous polyposis were excluded from the study. The data for the study was collected using a retrospective review of medical documentation. 
112 All subjects enrolled to the study, have been admitted to the ward a day before the ESD 113 procedure. Patients have been prepared for procedure with 4-L polyethylene glycol and have 114 received single-dose prophylactic antibiotic therapy. ESD was performed with iv. deep

115 sedation or general anesthesia with endotracheal intubation, at the discretion of the

116 endoscopist and anesthesiologist. Carbon dioxide was used for insufflation in all cases. ESD

117 was performed using the following procedures, as previously described: normal saline with

118 indygocarmine and/or sodium hyaluronate were injected into the submucosal layer around the

119 lesion to raise the mucosal layer [7]. An incision into the mucosa was performed outside the 120 target lesion. The subsequent submucosal dissection of the lesion was performed with a Dual

121 Knife (Olympus Medical Systems, Tokyo, Japan) and/or a Flush Knife-BT (ball tip; Fujifilm,

122 Tokyo, Japan). Traction force during dissection was achieved through gravity. Erbe VIO-

123 300S electrosurgical units (ERBE® Elektromedizin GmBH, Tübingen, Germany) were used

124 ("endo-cut effect 2" for mucosal incision and "swift coagulation mode effect 4/30 W" for

125 submucosal dissection and hemostasis). A Coagrasper (Olympus ${ }^{\circledR}$ ) was used for hemostasis

126 whenever necessary (soft coagulation effect $5 / 80 \mathrm{~W}$ ). The procedure was performed by single

127 well-trained operator. His learning curve points were analyzed and recently published in peer128 reviewed journals [17-20].

129

130 Histopathological assessment

131 All resected specimens were immersed in $10 \%$ formalin and sectioned serially at $2 \mathrm{~mm}$ 132 intervals. All tissue specimens were stained with hematoxylin and eosin. Afterwards, they 133 underwent histopathological evaluation by pathologists in accordance with the Vienna 134 classification and the World Health Organization classification of CRC [21,22]. 
Histopathological evaluation of resected en bloc lesions involved the assessment of lateral margins of dissection and the depth of SMI.

137

\section{Definition of complication and outcome measures}

139 En bloc resection was defined as resection of the rectal tumor in a one single tissue specimen.

140 Complete histologic resection (R0) was defined as an excision of the lesion with negative

141 lateral and deep margins. Incomplete histological resection was defined as failure to achieve

142 neoplasia-negative margins (R1). Curative ESD procedure was defined when all the following

143 criteria were met: (1) resected lesion with negative lateral and deep margins of cancer cells,

144 (2) depth of SMI $<1000 \mu \mathrm{m}$ below the muscularis mucosae, (3) absence of poorly

145 differentiated or mucinous histology, (4) absence of lymphovascular involvement and tumor

146 budding, and (5) without severe complication requiring additional surgical treatment. We

147 defined a superficial invasive cancer as a lesion with SMI invasion $<1000 \mu \mathrm{m}$ below the

148 muscularis mucosae.

149 In our study, the post-procedural bleeding has been defined as symptomatic bleeding with loss

150 above $2 \mathrm{~g} / \mathrm{dl}$ of hemoglobin level after finish of ESD procedure. Other adverse events reported

151 in the study were defined accordingly to recent criteria by the American Society of

152 Gastrointestinal Endoscopy [23].

153 Primary outcomes of the study were the En bloc, R0 and curative rates of the overall analyzed

154 group. The secondary outcomes involved the analysis of en bloc, R0 and curative rates in the

155 group of patients with invasive cancer and the complication rates in general group.

\section{Statistical analysis}

157 The data gathered in the study were analyzed with the statistical package Statistica 13.1

158 (StatSoft, Inc., USA). The speed of the procedure $(\mathrm{cm} 2 / \mathrm{min})$ were calculated on assumption

159 that every lesion had a congenial shape to the circle (thus $A=p r 2$ formula was used). The 
analyzed results were presented as mean \pm standard deviation regarding continuous variables and as numbers and percentage referring to categorical variables. Receiver operating characteristic (ROC) curves were constructed, and the areas under the ROC curves with 95\% CIs were calculated and compared with each other. The estimation of normality of distribution of the examined quantitative parameters was executed with the W Shapiro-Wilk test. The comparisons of the study groups were performed with the Student's t-test (or nonparametric the Mann-Whitney test, depending on the distribution of variables) and the chisquared test (or Fischer test). In all the analyses the probability value $\mathrm{p}<0.05$ was considered statistically significant. A multivariate logistic regression was carried out to identify factors related to the curative ESD rate and the following variables as explanatory variables: patient age, sex, tumor diameter, lesion location, recurrence character, presence of neoplasm invasion. Stepwise model selection was used for final variable selection ( $\mathrm{p}$-value $<0.05$ for model entry and p-value $>0.1$ to exit the model).

\section{Ethical considerations}

The study was conducted in accordance with the ethical principles of the 1975 Declaration of Helsinki and the study protocol was approved by the Committee of Bioethics of Medical University of Lodz, Poland (RNN/191/20/KE, July 14, 2020).

\section{Results}

\section{Patients' baseline characteristics}

A cohort of 320 successive patients who underwent rectal ESD from January 2016 to December 2020 were enrolled in our study: 171 (53.4\%) men and 149 (46.6\%) women. The mean resected specimen size was $47.4 \pm 27.8 \mathrm{~mm}$ and located at a mean of $4.5 \pm 3.5 \mathrm{~cm}$ from the anal verge. The most of included cases were presented with tumors located in lower/middle part of rectum. However, the distance from anal verge varied in our study from 0 to $15 \mathrm{~cm}$. 
According to the Paris classification $71.7 \%(\mathrm{n}=229)$ of lesions were categorized as LST-G tumors and $10.3 \%(n=33)$ as LST-NG. $18.1 \%$ of $(n=58)$ tumors could not be certainly assessed according to the Gross morphology.77.5\% $(\mathrm{n}=248)$ of tumors are primary and $22.5 \%$ $(n=72)$ have recurrent character after prior ESD or EMR attempt. The baseline characteristics of all subjects are presented in Table 1.

\section{Procedural characteristics, outcomes and adverse events}

The mean procedure time was 82.0 minutes $( \pm 68.4)$. Average speed of procedure was $24.5 \mathrm{~mm}^{2} / \mathrm{min}$. The mean hospitalization stay was $4.17 \pm 1.18$ days. The histopathological results of resected lesions and ESD general procedural characteristics are summarized in Table 2.

Overall, en bloc resection of rectal tumors in ESD was achieved in 92.5\% (296/320) of patients. The en bloc resection rate was at a similar level in those lesions with involved anal sphincters versus tumors without involvement (93.85\% vs. $92.16 \%$; $=0.644$ ). The R0 resection was noted in $89.4 \%$ of patients $(286 / 320)$. The overall curative ESD rate was achieved in $85.94 \%(275 / 320)$ of patients. ESD treatment outcomes in relation to the recurrent characteristics of rectal lesions are presented in Table 3. In our study, we observed that en bloc resection was more troublesome and harder to achieve in group of larger tumors ( $4.58 \pm 2.67$ vs. $6.66 \pm 3.37 \mathrm{~cm} ; \mathrm{p}<0.001$; Figure 1$)$. The ROC curves were constructed to assign optimal cut-off values of tumor diameter associated with sustained high en bloc resection rate $(\mathrm{AUC}=0.705)$. The analysis showed that in patients with tumor diameter above $3.5 \mathrm{~cm}$ $(\mathrm{PPV}=11.4 \%, \mathrm{NPV}=100 \%)$ extra precautions should be implemented during the ESD procedure due to difficulties to achieve en bloc resection (Figure 2). Our study showed that the curative ESD rate was statistically higher in patients with tumors with smaller diameter $(4.58 \pm 2.68$ vs. $5.64 \pm 3.19 \mathrm{~cm} ; \mathrm{p}=0.029$; Figure 3$)$. 
In the study group, there were $11.87 \%$ (38/320) subjects with invasive cancer on final

211 histopathology. In superficially invasive cancers the en bloc resection was achieved in $86.8 \%$

212 of cases (33/38). The R0 resection was confirmed in $84.21 \%(32 / 38)$ cases. Curative ESD rate

213 in group of invasive cancer reached 52.63\% (20/38). In 18 patients, in which ESD was not

214 curative, were scheduled for surgery due to deep invasion $(n=10)$ or positive margins $(n=8)$.

215 The detailed association of Paris and LST classifications in relation to cancer invasion were

216 presented in Table 4.

217 In all, we observed procedure-related adverse events in $3.44 \%(11 / 320)$ of patients (Table 5).

218 In $1.87 \%(6 / 320)$ of patients we noted early bleeding within the 24 hours after procedure, and 219 only in $0.31 \%(1 / 320)$ delayed bleeding after 24 hours after ESD. All cases of bleeding

220 responded to endoscopic treatment. Perforation occurred in $1.25 \%$ of cases (4/320), and all

221 were closed endoscopically using mechanical therapy (clips) with full recovery.

222 Complications were observed more frequently in patients with large sized-tumors $(6.77 \pm 3.71)$

223 compared to less diameter-tumors $(4.66 \pm 2.72 \mathrm{~cm}$; $\mathrm{p}=0.026$; Figure 4$)$.

Analysis of treatment predictors

226 We have performed a multivariate logistic regression to identify predictors of non-curative

227 ESD procedure (Figure 5). Our study showed that tumor diameter (OR=1.12; 95\% CI: 1.01-

228 1.23) and invasive character of lesions (OR=3.14; 95\% CI: 2.15-4.57) were associated with

229 significantly higher odds ratio of non-curative ESD procedure (Figure 5), whereas location

$230(\mathrm{OR}=1.04 ; 95 \% \mathrm{CI}: 0.95-1.13)$, recurrent character $(\mathrm{OR}=1.07 ; 95 \% \mathrm{CI}: 0.74-1.54)$, and

231 gender (OR=1; 95\% CI: 0.73-1.37) had no significant predictive value.

232

233 Discussion 
Our study confirms the efficacy and safety of ESD procedure in treating rectal tumors

235 (curative rate 85.94\%) with low adverse effects (3.4\%).

236 Preoperative diagnosis and staging in case of rectal lesions is essential. Rectal tumors are

237 related with diagnostic challenge, whereas complex clinical decision making is necessary to

238 provide proper approach. Avoiding undertreatment and overtreatment, which are linked with

239 unnecessary mortality and morbidity rates, are crucial. Recently, it has been found that $13 \%$

240 of the rectal tumors preoperatively staged as benign turned out to be malignant [24], however

241 currently there are no available perfect staging modalities. In Western countries currently

242 most lesions that have been shown not overtly cancerous on endoscopic inspection has been

243 resected by piecemeal EMR. However, piecemeal EMR is related with an important negative

244 impact on optimal histological assessment. The probability of "covert" cancer is associated

245 with lesion morphology, size, and site within the colon. Regardless of morphology, all

246 clinically benign rectal lesions $>2 \mathrm{~cm}$ have above $5 \%$ risk of harboring a focus of "covert"

247 cancer [25,26]. In our study, 11.9\% (38/320) of patients SMI have been confirmed in final

248 histopathological evaluation. In those cases, the proper histopathological verification between

249 specific type of SMI is crucial for further treatment and piecemeal EMR do not allow for

250 accurate verification. Therefore, piecemeal EMR is inappropriate approach in at least $5 \%$ of

251 rectal tumors $>2 \mathrm{~cm}$. In our opinion, in all rectal tumors $>2 \mathrm{~cm}$ the local en bloc resection

252 should be performed.

253 Clinical staging of deep invasion (>T1 SM1) has been also reported accurately only in 50\% in 254 expert Western centers and local en bloc resection could have been sufficient in the other 50\% 255 of cases [26]. In our study, we have misclassified the SM infiltration of rectal lesion in $25626.32 \%(10 / 38)$ of cases, assessing the tumor as SM1, and it turned out to be histopathological 257 SM2/3. Our endoscopic assessment of the SM infiltration was effective in $73.68 \%(28 / 38)$ of 258 patients. Only detailed pathological evaluation of the specimen can finally confirm the deep 
margin and other important factors such as grading, budding and vessel invasion. The safety and feasibility of en bloc resections in the rectum, in combination with the preoperative staging limitations should lead to a shift away from piecemeal EMR to local en bloc resection of large rectal tumors. Furthermore, in a recent cost-effectiveness analysis by Bahin et al. was shown that an en bloc resections had been more financially profitable than a piecemeal EMR for rectal tumors by significantly reducing the numbers of patients demanding more radical surgical interventions [12]. It is a great place for ESD implementation as a technique that does not require an operating theater facility and enables en bloc resection of rectal lesions regardless of their size. In the study by Yamashita $\mathrm{K}$ et al. has been shown that the diagnostic ESD for SM2/3 rectal tumors do not affect the outcomes of subsequent surgery and long-term survival rate [27].

Another crucial advantage of local en bloc resection of possible malignant rectal tumors is improved quality of the histopathological assessment in terms of the deep margin evaluation. This observation has been confirmed in the TREND study where 3\% (3/87) of patients had developed cancer recurrence after removal of a pT0 tumor in the piecemeal EMR group, versus none in the group after en bloc TEM procedure [24]. Cancer recurrence at the removal site of a benign adenoma occurs in approximately $1-2 \%$ of patients $[28,29]$. A possible explanation is pathological under staging with small areas of invasion being missed in the histopathological examination of the piecemeal EMR specimens. The ESD technique in our study allowed for the removal of $92.5 \%$ of the lesions en bloc and provided good quality material for histopathological examination.

Our study analyzed the outcomes of the ESD technique for resection of rectal tumors, showing that this technique is effective, safe and may be potential equivalent option for TEM/TAMIS procedures. The overall curative ESD in our study was $85.67 \%$ and there were no differences between primary and recurrent lesions $(\mathrm{p}=0.736)$. We observed that rectal 
curative ESD rate was statistically higher in patients with tumors with a smaller diameter $(\mathrm{p}=0.029)$, which was confirmed in multivariate logistic regression which indicated that only tumor size and invasiveness are significant predictors of filed en bloc resection. Even though the cutoff point indicated in the ROC analysis in our study was $3.5 \mathrm{~cm}$, we achieved a relatively high overall en bloc resection rate (92.5\%). Our results are comparative to outcomes of ESD rectal procedures reported in meta-analysis by AP Naughton et al [30]. In our opinion, ESD in rectal tumors has important advantages over TEM/TAMIS approach. The localization of lesion or involvement of anal sphincters do not change the outcomes of endoscopic procedure. In our study, the en bloc rate of ESD among tumors involving anal sphincters was on a similar level compared to those without sphincters involvement $(93.85 \%$ vs. 92.16\%; $\mathrm{p}=0.644)$. Whereas TEM/TAMIS techniques in tumors involving anal canal or anal sphincters remains more troublesome. Moreover, ESD procedures are in general performed outside the operating room which significantly improves the cost-effectiveness outcomes of this approach.

Our study confirmed that rectal lesions can be safely removed in ESD procedure, which emphasizes the validity of the local surgical or endoscopic en bloc resection of rectal tumors. ESD and TAMIS as the two main techniques recommended for local resection of rectal lesions appear to be the most attractive in future. Guidelines published in 2017 recommended that a comparison between local surgical resection and ESD is warranted to guide decision making for the appropriate treatment management of rectal tumors in Western countries [31]. Therefore, the TRISSIC study protocol have been developed to evaluate the comparison between ESD and TAMIS, instead of TEM, because TAMIS provides the benefits of advanced videoscope transanal excision at a fraction of the cost of TEM [32,33]. In TAMIS technique, there are no requirements of additional investments and the TAMIS port with its shorter shaft length allow for increased working angle and more distal resection in relation to 
the TEM[34]. Maglio et al have noted that TAMIS is associated with lower risk of sphincters injury vs. TEM.[35].

311 Due to the lack of results of studies directly comparing TAMIS and ESD techniques, the 312 decision to choose one of them depends on the individual preferences of the operator.

313 However, the primary goal is to get the highest possible rate of local en bloc resection and 314 keep up low risk of complications. Our results showed that the ESD in the hands of a Western 315 endoscopist trained in accordance with the ESGE curriculum meets these assumptions. Based on the results of this study, the review of current literature and our experience we recommend guidelines for the endoscopic approach for rectal lesions in Figure 6.

Potential limitations of our study should be considered. First, our study has a retrospective observational character and some of results may be susceptible to bias and a type II error.

320 Second, our study included only patients from one endoscopic center treated by the same experienced endoscopist. Currently a prospective follow-up of included patients is ongoing to provide long-term follow-up data on the patients within our original cohort. Finally, above

323 limitations could be circumvented with further investigations involving other endoscopists 324 and centers, which will have a low risk of bias or a type II error.

\section{Conclusions}

327 In conclusions, we have observed that ESD in rectal tumors is safe approach with high 328 curative rate, even in difficult lesions. Diagnostic ESD en bloc resection in early-stage rectal 329 cancers may be an important alternative in improvement of the preoperative staging methods. 330 ESD approach should have been considered for all rectal tumors, especially those lesions suspected for SMI, as it can serve as a staging method and may have been curative for 332 adenomas and invasive cancers limited to the mucosa. In our opinion one of local resection 
333 techniques (ESD or TEM/TAMIS) should be present in every colorectal center to facilitate 334 rectal tumor treatment.

335 


\section{References}

337 1. Bray, F.; Ferlay, J.; Soerjomataram, I.; Siegel, R.L.; Torre, L.A.; Jemal, A. Global cancer statistics 2018: GLOBOCAN estimates of incidence and mortality worldwide for 36 cancers in 185 countries. CA. Cancer J. Clin. 2018, 68, 394-424.

2. Weitz, J.; Koch, M.; Debus, J.; Höhler, T.; Galle, P.R.; Büchler, M.W. Colorectal cancer. In Proceedings of the Lancet; Lancet, 2005; Vol. 365, pp. 153-165.

3. Jankowski, M.; Bała, D.; Las-Jankowska, M.; Wysocki, W.M.; Nowikiewicz, T.; Zegarski, W. Overall treatment outcome - analysis of long-term results of rectal cancer treatment on the basis of a new parameter. Arch. Med. Sci. 2020, 16, 825-833.

4. Näsvall, P.; Dahlstrand, U.; Löwenmark, T.; Rutegård, J.; Gunnarsson, U.; Strigård, K. Quality of life in patients with a permanent stoma after rectal cancer surgery. Qual. Life Res. 2017, 26, 55-64.

5. Pimentel-Nunes, P.; Dinis-Ribeiro, M.; Ponchon, T.; Repici, A.; Vieth, M.; De Ceglie,

352 6. Nam, M.J.; Sohn, D.K.; Hong, C.W.; Han, K.S.; Kim, B.C.; Chang, H.J.; Park, S.C.; 2015, 89, 202-207.

7. Ahlenstiel, G.; Hourigan, L.F.; Brown, G.; Zanati, S.; Williams, S.J.; Singh, R.; Moss, A.; Sonson, R.; Bourke, M.J. Actual endoscopic versus predicted surgical mortality for treatment of advanced mucosal neoplasia of the colon. Gastrointest. Endosc. 2014, 80, $668-676$. 
T.; Watanabe, M.; Yoshida, M.; et al. Japan Gastroenterological Endoscopy Society guidelines for colorectal endoscopic submucosal dissection/endoscopic mucosal resection. Dig. Endosc. 2020, 32, 219-239.

9. Draganov, P. V.; Wang, A.Y.; Othman, M.O.; Fukami, N. AGA Institute Clinical Practice Update: Endoscopic Submucosal Dissection in the United States. Clin. Gastroenterol. Hepatol. 2019, 17, 16-25.e1.

10. Akintoye, E.; Kumar, N.; Aihara, H.; Nas, H.; Thompson, C. Colorectal endoscopic submucosal dissection: a systematic review and meta-analysis. Endosc. Int. Open 2016, 04, E1030-E1044.

11. Burgess, N.G.; Bourke, M.J. Endoscopic resection of colorectal lesions: The narrowing divide between East and West. Dig. Endosc. 2016, 28, 296-305.

12. Bahin, F.F.; Heitman, S.J.; Rasouli, K.N.; Mahajan, H.; McLeod, D.; Lee, E.Y.T.; Williams, S.J.; Bourke, M.J. Wide-field endoscopic mucosal resection versus endoscopic submucosal dissection for laterally spreading colorectal lesions: A costeffectiveness analysis. Gut 2018, 67, 1965-1973.

13. Holmes, I.; Friedland, S. Endoscopic mucosal resection versus endoscopic submucosal dissection for large polyps: A western colonoscopist's view. Clin. Endosc. 2016, 49, $454-456$.

14. Fujishiro, M.; Yahagi, N.; Kakushima, N.; Kodashima, S.; Muraki, Y.; Ono, S.; Submucosal Dissection for Colorectal Epithelial Neoplasms in 200 Consecutive Cases. Clin. Gastroenterol. Hepatol. 2007, 5, 678-683.

15. McCarty, T.R.; Bazarbashi, A.N.; Hathorn, K.E.; Thompson, C.C.; Aihara, H. Endoscopic submucosal dissection (ESD) versus transanal endoscopic microsurgery (TEM) for treatment of rectal tumors: a comparative systematic review and meta- 
analysis. Surg. Endosc. 2020, 34, 1688-1695.

16. Sagae, V.M.T.; Ribeiro, I.B.; de Moura, D.T.H.; Brunaldi, V.O.; Logiudice, F.P.; Funari, M.P.; Baba, E.R.; Bernardo, W.M.; de Moura, E.G.H. Endoscopic submucosal dissection versus transanal endoscopic surgery for the treatment of early rectal tumor: a systematic review and meta-analysis. Surg. Endosc. 2020, 34, 1025-1034.

17. Spychalski, M.; Zelga, P.; Dziki, A. Key factors in achieving successful endoscopic dissection of rectal tumors: Early results of 33 consecutive rectal endoscopic submucosal dissections in polish academic center. Surg. Laparosc. Endosc. Percutaneous Tech. 2015, 25, 173-177.

18. Spychalski, M.; Dziki, A. Safe and efficient colorectal endoscopic submucosal dissection in European settings: Is successful implementation of the procedure possible? Dig. Endosc. 2015, 27, 368-373.

19. Spychalski, M.; Skulimowski, A.; Dziki, A.; Saito, Y. Colorectal endoscopic submucosal dissection (ESD) in the West-when can satisfactory results be obtained? A single-operator learning curve analysis. Scand. J. Gastroenterol. 2017, 52, 1442-1452.

20. Spychalski, M.; Skulimowski, A.; Nishimura, M.; Dziki, A. Comparison of Endoscopic Submucosal Dissection for Primary and Recurrent Colorectal Lesions: A Single-Center European Study. J. Laparoendosc. Adv. Surg. Tech. 2019, 29, 366-373.

21. Rubio, C.A.; Nesi, G.; Messerini, L.; Zampi, G.C.; Mandai, K.; Itabashi, M.; Takubo, K. The Vienna classification applied to colorectal adenomas. J. Gastroenterol. Hepatol. 2006, 21, 1697-1703.

22. Nagtegaal, I.D.; Odze, R.D.; Klimstra, D.; Paradis, V.; Rugge, M.; Schirmacher, P.; Washington, K.M.; Carneiro, F.; Cree, I.A. The 2019 WHO classification of tumours of the digestive system. Histopathology 2020, 76, 182-188.

23. Kothari, S.T.; Huang, R.J.; Shaukat, A.; Agrawal, D.; Buxbaum, J.L.; Abbas Fehmi, 
S.M.; Fishman, D.S.; Gurudu, S.R.; Khashab, M.A.; Jamil, L.H.; et al. ASGE review of adverse events in colonoscopy. Gastrointest. Endosc. 2019, 90, 863-876.e33.

413

414

24. Barendse, R.M.; Musters, G.D.; de Graaf, E.J.R.; van den Broek, F.J.C.; Consten, E.C.J.; Doornebosch, P.G.; Hardwick, J.C.; de Hingh, I.H.J.T.; Hoff, C.; Jansen, J.M.; et al. Randomised controlled trial of transanal endoscopic microsurgery versus endoscopic mucosal resection for large rectal adenomas (TREND Study). Gut 2018, 67, 837-846.

25. Burgess, N.G.; Hourigan, L.F.; Zanati, S.A.; Brown, G.J.; Singh, R.; Williams, S.J.; Raftopoulos, S.C.; Ormonde, D.; Moss, A.; Byth, K.; et al. Risk Stratification for Covert Invasive Cancer Among Patients Referred for Colonic Endoscopic Mucosal Resection: A Large Multicenter Cohort. Gastroenterology 2017, 153, 732-742.e1.

26. Moss, A.; Bourke, M.J.; Williams, S.J.; Hourigan, L.F.; Brown, G.; Tam, W.; Singh, R.; Zanati, S.; Chen, R.Y.; Byth, K. Endoscopic mucosal resection outcomes and prediction of submucosal cancer from advanced colonic mucosal neoplasia. Gastroenterology 2011, 140, 1909-1918.

27. Yamashita, K.; Oka, S.; Tanaka, S.; Nagata, S.; Hiraga, Y.; Kuwai, T.; Furudoi, A.; Tamura, T.; Kunihiro, M.; Okanobu, H.; et al. Preceding endoscopic submucosal dissection for $\mathrm{T} 1$ colorectal carcinoma does not affect the prognosis of patients who underwent additional surgery: a large multicenter propensity score-matched analysis. $J$. Gastroenterol. 2019, 54, 897-906.

28. Saito, Y.; Fukuzawa, M.; Matsuda, T.; Fukunaga, S.; Sakamoto, T.; Uraoka, T.; Nakajima, T.; Ikehara, H.; Fu, K.-I.; Itoi, T.; et al. Clinical outcome of endoscopic submucosal dissection versus endoscopic mucosal resection of large colorectal tumors as determined by curative resection. Surg. Endosc. 2010, 24, 343-352.

29. Van Den Broek, F.J.C.; De Graaf, E.J.R.; Dijkgraaf, M.G.W.; Reitsma, J.B.; 
Haringsma, J.; Timmer, R.; Weusten, B.L.A.M.; Gerhards, M.F.; Consten, E.C.J.; Schwartz, M.P.; et al. Transanal endoscopic microsurgery versus endoscopic mucosal resection for large rectal adenomas (TREND-study). BMC Surg. 2009, 9, 4.

30. Naughton, A.P.; Ryan, É.J.; Bardon, C.T.; Boland, M.R.; Aherne, T.M.; Kelly, M.E.; Whelan, M.; Neary, P.C.; McNamara, D.; O’Riordan, J.M.; et al. Endoscopic management versus transanal surgery for early primary or early locally recurrent rectal neoplasms - a systematic review and meta-analysis. Int. J. Colorectal Dis. 2020, 35 , $2347-2359$.

31. Ferlitsch, M.; Moss, A.; Hassan, C.; Bhandari, P.; Dumonceau, J.M.; Paspatis, G.; Jover, R.; Langner, C.; Bronzwaer, M.; Nalankilli, K.; et al. Colorectal polypectomy and endoscopic mucosal resection (EMR): European Society of Gastrointestinal Endoscopy (ESGE) Clinical Guideline. Endoscopy 2017, 49, 270-297.

32. Dekkers, N.; Boonstra, J.J.; Moons, L.M.G.; Hompes, R.; Bastiaansen, B.A.; Tuynman, J.B.; Koch, A.D.; Weusten, B.L.A.M.; Pronk, A.; Neijenhuis, P.A.; et al. Transanal minimally invasive surgery (TAMIS) versus endoscopic submucosal dissection (ESD) for resection of non-pedunculated rectal lesions (TRIASSIC study): Study protocol of a European multicenter randomised controlled trial. BMC Gastroenterol. 2020, 20, 1-9.

33. Atallah, S.; Albert, M.; Larach, S. Transanal minimally invasive surgery: A giant leap forward. Surg. Endosc. 2010, 24, 2200-2205.

34. Martin-Perez, B.; Andrade-Ribeiro, G.D.; Hunter, L.; Atallah, S. A systematic review of transanal minimally invasive surgery (TAMIS) from 2010 to 2013. Tech. Coloproctol. 2014, 18, 775-788.

35. Maglio, R.; Marco Muzi, G.; Meucci Massimo, M.; Masoni, L. Transanal minimally invasive surgery (Tamis): New treatment for early rectal cancer and large rectal polypsexperience of an Italian center. Am. Surg. 2015, 81, 273-277. 
461

462 
464 Table 1. Baseline characteristics of the study group

465 Table 2. Endoscopic submucosal dissection procedural characteristics.

466 Table 3. Endoscopic submucosal dissection treatment outcomes in relation to the recurrent

467 characteristics of rectal lesions

468 Table 4. The detailed association of Paris and LST classifications in relation to cancer

469 invasion.

470 Table 5. Adverse effects of ESD procedure in rectal tumors

471

472 Figure 1. The reletionship of tumor diamater and en bloc resection in rectal tumors

$473 \quad(4.58 \pm 2.67$ vs. $6.66 \pm 3.37 ; \mathrm{p}<0.001)$

474 Figure 2. Receiver operating characteristic curve for tumor diameter and the en bloc resection

475 rate with indicated cutoff point for $3.5 \mathrm{~cm}$ (100\% sensitivity, $34,1 \%$ specificity).

476 Figure 3. The relationship between the curative ESD rate of endoscopic submucosal resection

477 of rectal tumors and diameter of lesion ( $4.58 \pm 2.68$ vs. $5.64 \pm 3.19 ; \mathrm{p}=0.029)$.

478 Figure 4. The relationship between tumor diameter and occurrence of sever adverse events

$479 \quad(6.77 \pm 3.71 \mathrm{~cm}$ vs. $4.66 \pm 2.72 ; \mathrm{p}=0.026)$.

480 Figure 5. Forrest plot presenting the odds ratio for achieving a curative ESD procedure.

481 Figure 6. The proposed guidelines for the endoscopic approach for rectal lesions. 


\begin{tabular}{|c|c|c|}
\hline \multicolumn{2}{|l|}{ Age (years) } & $64.69 \pm 11.06$ \\
\hline \multirow{2}{*}{ Sex } & Female & $149(46.56 \%)$ \\
\hline & Male & $171(53.44 \%)$ \\
\hline \multicolumn{2}{|l|}{ Primary tumor } & $248(77.5 \%)$ \\
\hline \multicolumn{2}{|l|}{ Recurrence after EMR } & $72(22.5 \%)$ \\
\hline \multirow{3}{*}{ Gross morphology } & LST-G & $229(71.56 \%)$ \\
\hline & LST-NG & $33(10.31 \%)$ \\
\hline & $\mathrm{n} / \mathrm{a}$ & $58(18.12 \%)$ \\
\hline \multirow{5}{*}{ Paris Classification } & IIa & $144(45 \%)$ \\
\hline & $\mathrm{IIa}+\mathrm{c}$ & $52(16.3 \%)$ \\
\hline & IIa+Is & $74(23.1 \%)$ \\
\hline & Is & $48(15 \%)$ \\
\hline & Is +IIa & $2(0.6 \%)$ \\
\hline
\end{tabular}

Table 1. Baseline characteristics of the study group (n/a - not assessed; EMR - endoscopic mucosal resection) 


\begin{tabular}{|c|c|c|}
\hline \multirow[t]{5}{*}{$\begin{array}{l}\text { Histopathological } \\
\text { evaluation }\end{array}$} & $\begin{array}{l}\text { Adenoma minor } \\
\text { dysplasia }\end{array}$ & $91(28.44 \%)$ \\
\hline & $\begin{array}{l}\text { Adenoma major } \\
\text { dysplasia }\end{array}$ & $144(45 \%)$ \\
\hline & $\begin{array}{l}\text { Invasive } \\
\text { adenocarcinoma }\end{array}$ & $38(11.87 \%)$ \\
\hline & $\begin{array}{l}\text { Carcinoma in } \\
\text { situ }\end{array}$ & $44(13.75)$ \\
\hline & $\begin{array}{l}\text { Sessile serrated } \\
\text { adenoma }\end{array}$ & $3(0.94 \%)$ \\
\hline \multicolumn{2}{|l|}{ Tumor size $[\mathrm{cm}]$} & $4.74 \pm 2.78$ \\
\hline \multicolumn{2}{|c|}{ Mean procedure time [min] } & $82.89 \pm 68.4$ \\
\hline \multicolumn{2}{|c|}{$\begin{array}{l}\text { Average speed of tumor dissection } \\
{\left[\mathrm{mm}^{2} / \mathrm{min}\right]}\end{array}$} & $24.5 \pm 14.59$ \\
\hline \multicolumn{2}{|c|}{ Length from anal verge $[\mathrm{cm}]$} & $4.51 \pm 3.5$ \\
\hline
\end{tabular}

Table 2. Endoscopic submucosal dissection procedural characteristics. 


\begin{tabular}{|l|l|l|l|}
\hline & $\begin{array}{l}\text { Primary tumour } \\
\mathrm{n}=248(77.5 \%)\end{array}$ & $\begin{array}{l}\text { Recurrent tumour } \\
\mathrm{n}=72(22.5 \%)\end{array}$ & $\mathrm{p}$-value \\
\hline En bloc & $233(93.95 \%)$ & $63(87.5 \%)$ & $\mathrm{p}=0.067$ \\
\hline R0 & $225(90.73 \%)$ & $61(84.72 \%)$ & $\mathrm{p}=0.146$ \\
\hline Curative ESD rate & $214(86.29 \%)$ & $61(84.72 \%)$ & $\mathrm{p}=0.736$ \\
\hline
\end{tabular}

Table 3. Endoscopic submucosal dissection treatment outcomes in relation to the recurrent characteristics of rectal lesions 


\begin{tabular}{|c|c|c|c|c|}
\hline & & Invasive cancer & No invasive lesion & $\mathrm{p}$ \\
\hline \multirow{5}{*}{$\begin{array}{c}\text { Paris } \\
\text { classification }\end{array}$} & IIa & $9(6.25 \%)$ & $135(93.75 \%)$ & \multirow{5}{*}{$\mathrm{p}=0.002$} \\
\hline & Is & $11(22.92 \%)$ & $37(77.08 \%)$ & \\
\hline & $\mathrm{IIa}+\mathrm{C}$ & $12(23.08 \%)$ & $40(76.92 \%)$ & \\
\hline & $\mathrm{IIa}+\mathrm{Is}$ & $6(8.11 \%)$ & $68(91.89 \%)$ & \\
\hline & Is +IIA & 0 & $2(100 \%)$ & \\
\hline \multirow{2}{*}{$\begin{array}{c}\text { LST } \\
\text { classification }\end{array}$} & LST-NG & $10(30.3 \%)$ & $23(69.7 \%)$ & \multirow{2}{*}{$\mathrm{p}<0.001$} \\
\hline & LST-G & $20(8.73 \%)$ & $209(91.27 \%)$ & \\
\hline
\end{tabular}

Table 4. The detailed association of Paris and LST classifications in relation to cancer invasion. 


\begin{tabular}{|l|l|}
\hline $\begin{array}{l}\text { Early bleeding }(<24 \text { hours after ESD } \\
\text { procedure })\end{array}$ & $\mathrm{n}=6(1.87 \%)$ \\
\hline Delayed bleeding $(>24$ hours after ESD $)$ & $\mathrm{n}=1(0.31 \%)$ \\
\hline Perforation & $\mathrm{n}=4(1.25 \%)$ \\
\hline
\end{tabular}

Table 5. Adverse effects of ESD procedure in rectal tumors 


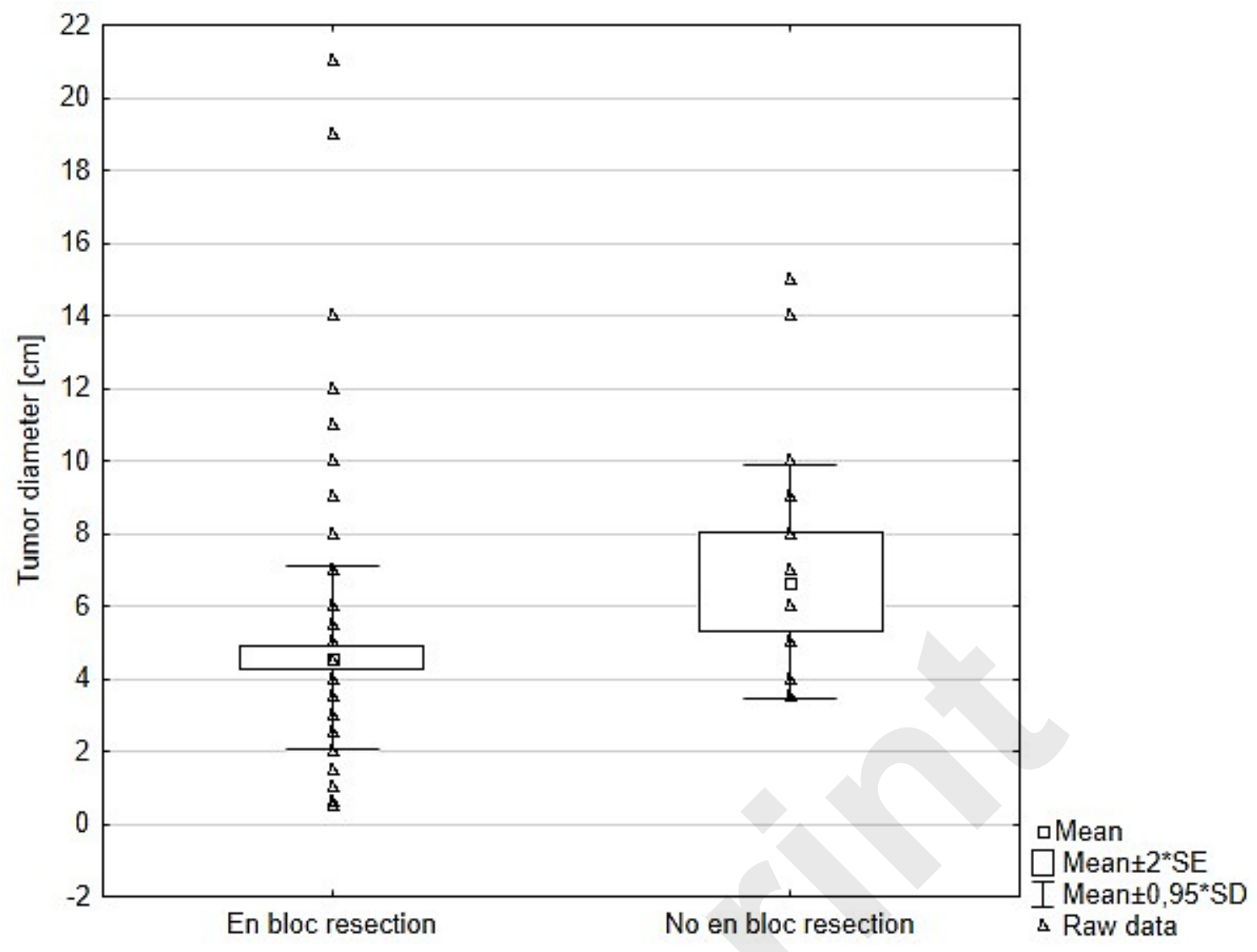

Figure 1. The reletionship of tumor diamater and en bloc resection in rectal tumors $(4.58 \pm 2.67$ vs. $6.66 \pm 3.37 ; p<0.001)$ 


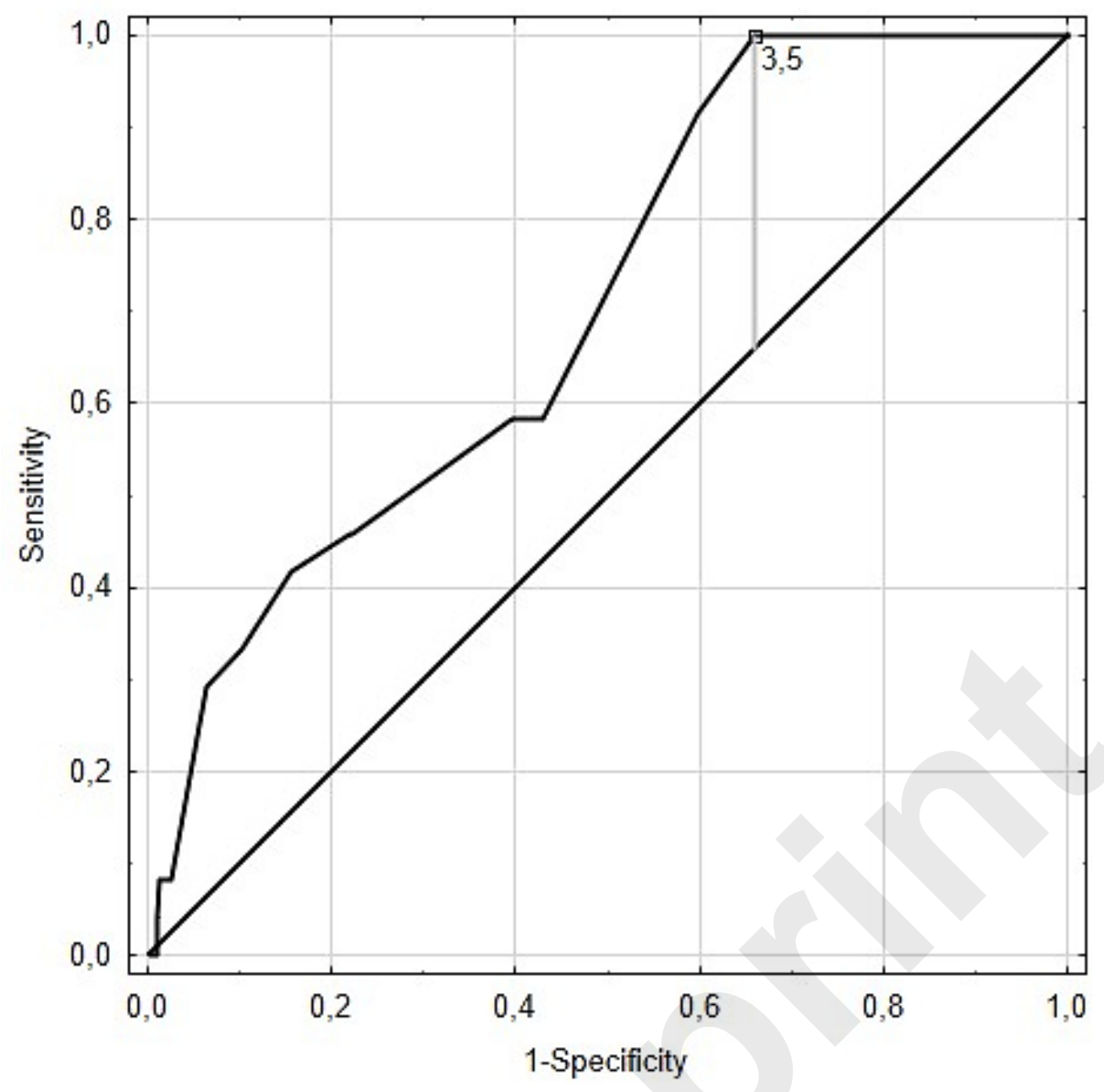

Figure 2. Receiver operating characteristic curve for tumor diameter and the en bloc resection rate with indicated cutoff point for $3.5 \mathrm{~cm}$ (100\% sensitivity, $34,1 \%$ specificity). 


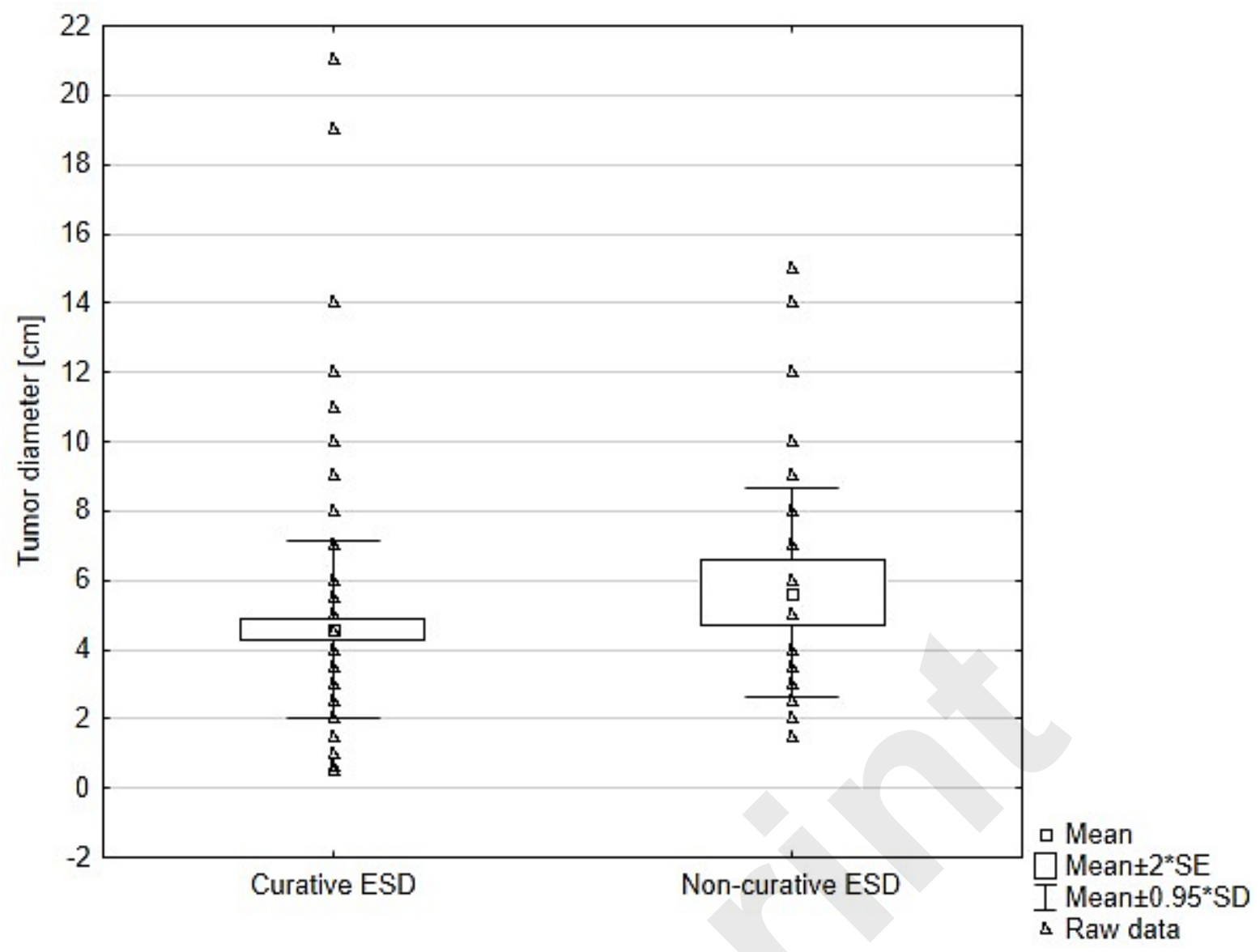

Figure 3. The relationship between the curative ESD rate of endoscopic submucosal resection of rectal tumors and diameter of lesion $(4.58 \pm 2.68$ vs. $5.64 \pm 3.19 ; p=0.029)$. 


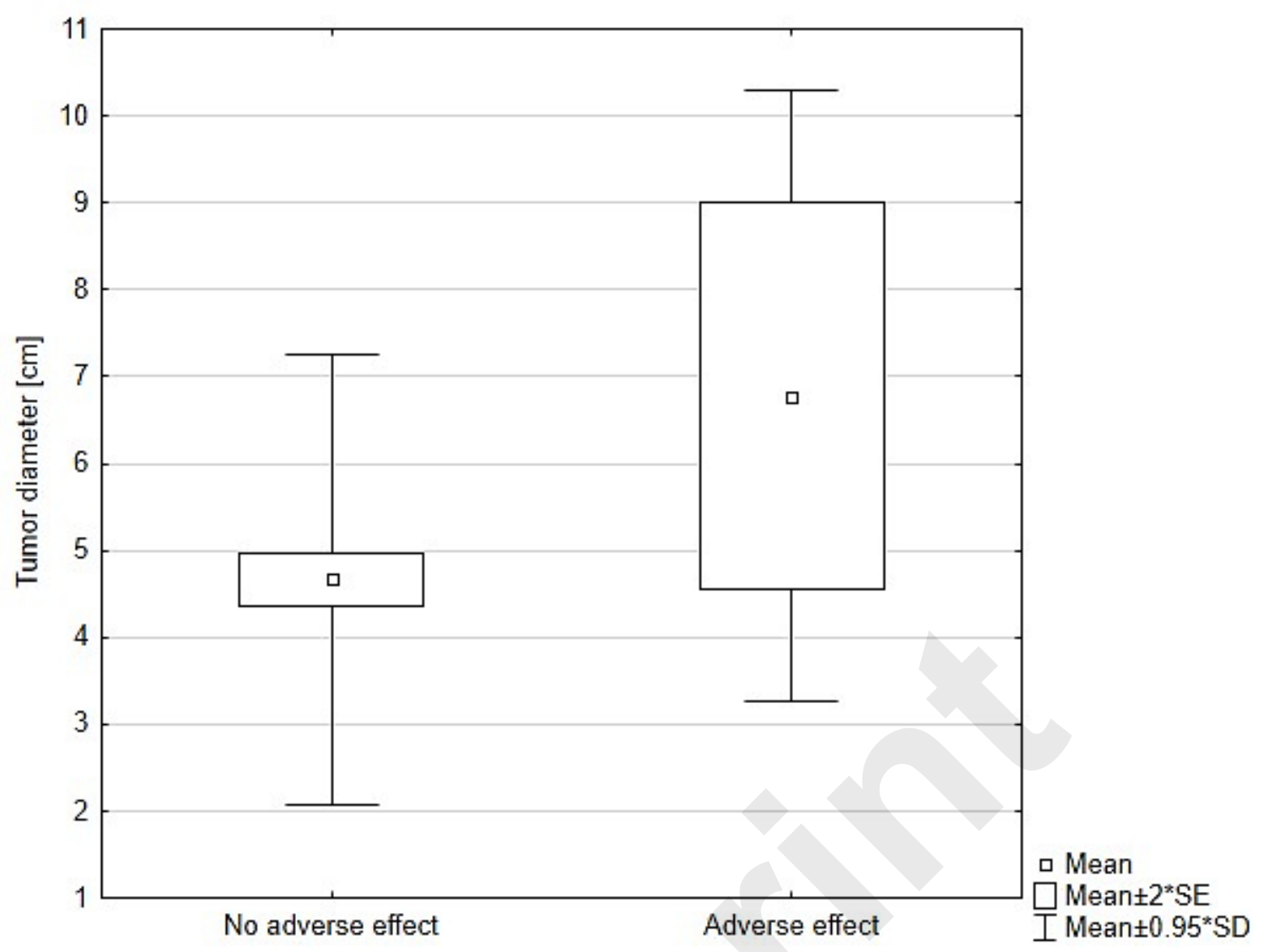

Figure 4. The relationship between tumor diameter and occurrence of sever adverse events $(6.77 \pm 3.71 \mathrm{~cm}$ vs. $4.66 \pm 2.72 ; p=0.026)$. 


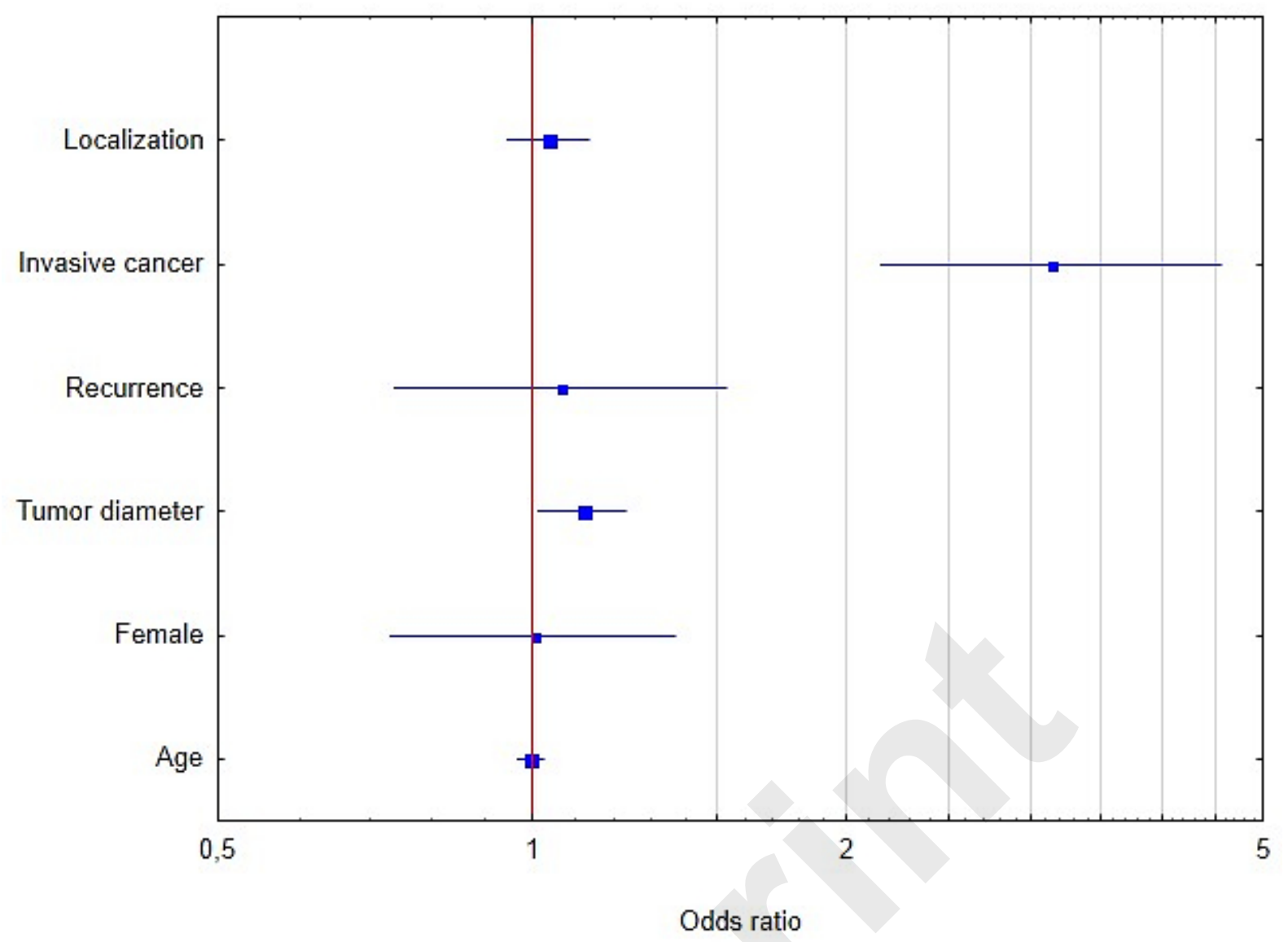

Figure 5. Forrest plot presenting the odds ratio for achieving a curative ESD procedure. 


\section{Rectal tumor/polyp: en block resection mandatory in case of any risk of malignancy}

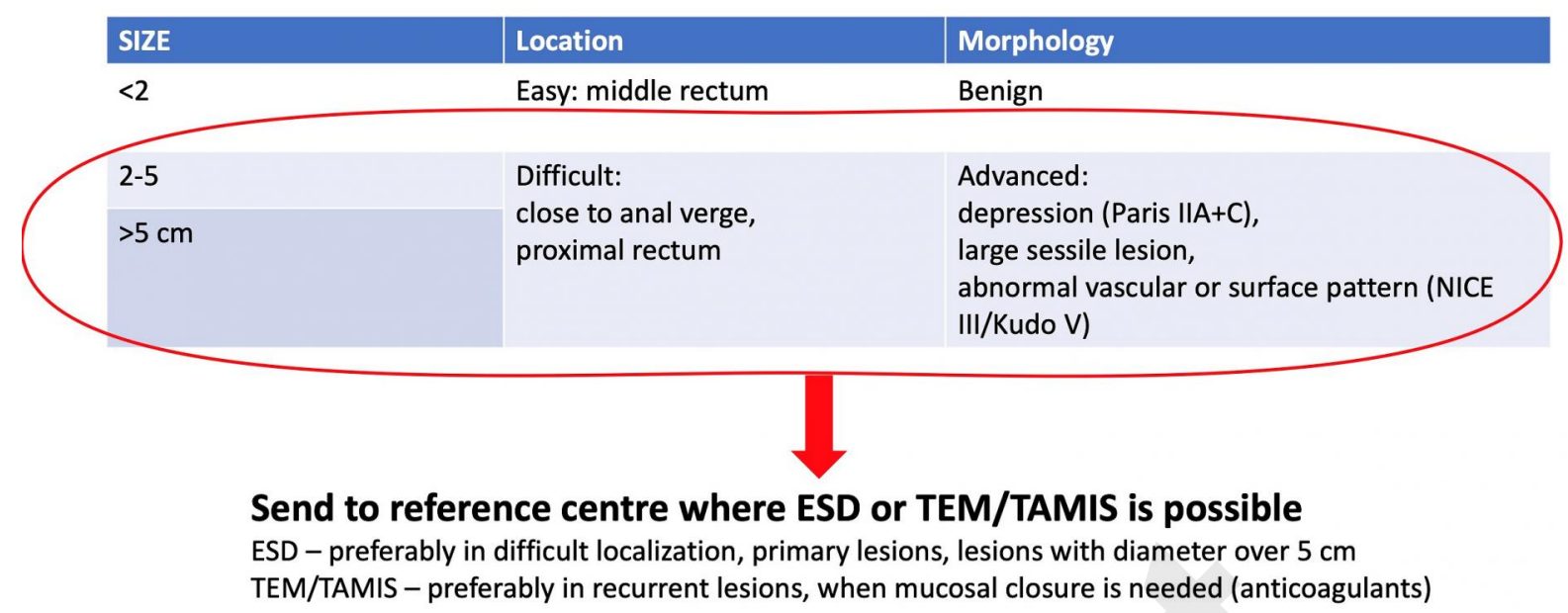

Figure 6. The proposed guidelines for the endoscopic approach for rectal lesions. 